\title{
Synthesis, Characterization and Applications of Nanochitosan/Sodium Alginate/Microcrystalline Cellulose Film
}

Vijayalakshmi $\mathrm{K}^{1}$, Devi $\mathrm{BM}^{2}$, Sudha $\mathrm{PN}^{1 *}$, Venkatesan $\mathrm{J}^{3}$ and Anil $\mathrm{S}^{4 *}$

${ }^{1}$ Department of Chemistry, DKM College for Women, Vellore, Tamilnadu, India

${ }^{2}$ Department of Chemistry, Bharathiar University, Coimbatore, India

${ }^{3}$ Marine Bioprocess Research Center and Department of Marine-bio Convergence Science, Pukyong National University, Busan, Republic of Korea

${ }^{4}$ Division of Periodontics, Department of PDS, College of Dentistry, Prince Sattam Bin Abdulaziz University, Riyadh, Saudi Arabia

\begin{abstract}
The antimicrobial potential of the synthesized ternary nanochitosan (NCS)/sodium alginate (SA)/microcrystalline cellulose (MC) (extracted from banana fiber) film in 4:16:1 ratio against Bascillus subtilis and $E$. coli are reported here. Initially the present work focuses on the synthesis and characterization of ternary nanochitosan (NCS)/sodium alginate (SA)/microcrystalline cellulose (MC) (extracted from banana fiber) film. The prepared NCS/SA/MC film sample was then characterized using advanced analytical techniques such as FT-IR, XRD, TGA, DSC and SEM studies. The obtained results of FT-IR studies clearly indicate that the nanochitosan gets effectively binded with the sodium alginate and the microcrystalline cellulose in the film form. The change in crystallinity and the increased thermal behavior was elucidated from XRD and TGA analysis respectively. The scanning electron microscopic (SEM) studies of NCS/SA/MC film showed that the prepared film has the improved rough surface morphology and fractured structure. The bactericidal action of NCS/SA/MC film determined using Muller Hinton Agar medium on two microbial strains (Escherichia coli and Bacillus subtilis) reveals that the prepared NCS/SA/MC film has the greater potential to kill the microorganisms to a greater extent and hence this NCS/SA/MC film was found to be suggested as the promising material for biomedical applications.
\end{abstract}

Keywords: Nanochitosan; Sodium alginate; Microcrystalline cellulose; Antimicrobial activity

\section{Introduction}

Pathogenic bacteria remain a major health concern especially since it is responsible for causing a large number of deaths and hospitalizations each year [1]. Recently one of the major issues and concern for governments around the globe were the antimicrobial resistance inside an extensive variety of infectious agents [2]. It is a public wellbeing menace that influences nations and various fields which, in turn, undermine to the achievements of modern medicine [3]. The synthesis and biocide mpacts of novel compounds were severely studied consequently [4]. In recent years, the risk of infection caused by microorganisms is of major concern in clinical, pharmaceutical areas (drugs, medical devices, odontology, hospital surfaces, etc.) and as well as in the food industries (food packaging, storage, fresh products, etc.). About two million peoples were affected by the bacterial infections in hospitals each year and this was reported according to the centers of disease control and prevention, Department of Health and Human Services, USA [5]. Gram-positive organism including Bacillus subtilis and gram negative bacteria including $E$. coli, were among the top 10 most frequently isolated organisms which produces too many infectitious diseases to the humans, in severe cases lead to death too.

In order to improve the protection against pathogenic bateria it is ncecessary to introduce the new and effective/efficient antibacterial therapeutics and diagnostics which appears to be highly relevant in health care. At an alarming rate, eventhough we have current treatments such as antibiotics which proved as effective against multidrug-resistant bacteria, the pathogens evolved effective mechanisms to counter the biocidal action of antibiotics [6]. The emergence of resistance to conventional antimicrobials necessitates constant development of newer agents, which can inhibit the growth of resistant organisms. The use of substances with antimicrobial properties to treat the infections is known to have been common practice for at least 2000 years and so a large amount of intensive researches was made by various researchers recently leading to the formation of new materials, which would assure permanent bioactive effects together with complete safety for the people $[7,8]$.

A large group of the studies includes the implementation of nanomaterials and nanotechnologies to create new antibacterial agents that increased effectiveness and efficiency $[9,10]$. Among the numerous materials having the antimicrobial feature, in the present research work, the three materials namely the nanochitosan, sodium alginate and cellulose extracted from the banana fiber can be highlighted. The biopolymeric chitosan $\mathrm{N}$-deacetylated derivative of chitin isolated from shellfish, crab and shrimp has been reported to exhibit numerous health-related beneficial effects, including strong antimicrobial and antioxidative activities. The chitosan biopolymer has been chosen in this work due to its biodegradable, non antigenic, biocompatible, non toxic nature and the ability of transformation into gels, beads, fibers, colloids, films, flakes, powders, capsules [11,12]. The antibacterial activity of chitosan was mainly influenced by bacterial species, concentration, $\mathrm{pH}$, solvent and molecular mass [13].

Recently, there have been significant scientific interests to scientists

*Corresponding authors: Sukumaran Anil, Division of Periodontics, Department of PDS, College of Dentistry, Prince Sattam Bin Abdulaziz University, Riyadh Saudi Arabia, Tel: 9842910157; E-mail: drparsu8@gmail.com

Sudha PN, PG and Research Department of Chemistry, DKM College for Women Vellore, Tamilnadu, India, Tel: 9842910157; E-mail: drparsu8@gmail.com

Received November 21, 2016; Accepted December 27, 2016; Published December 31, 2016

Citation: Vijayalakshmi K, Devi BM, Sudha PN, Venkatesan J, Anil S (2016) Synthesis, Characterization and Applications of Nanochitosan/Sodium Alginate/ Microcrystalline Cellulose Film. J Nanomed Nanotechnol 7: 419. doi: 10.4172/21577439.1000419

Copyright: (c) 2016 Vijayalakshmi K, et al. This is an open-access article distributed under the terms of the Creative Commons Attribution License, which permits unrestricted use, distribution, and reproduction in any medium, provided the original author and source are credited. 
for the chemical modifications of chitosan to increase its applications [14]. The modified chitosan have attracted lots of interest especially regarding its bactericidal property against several types of bacteria [15]. Due to high aspect ratio and surface area, the nano-sized composites (nanoparticles, nanomaterials) are expected to be more effective in penetrating and disrupting bacterial cell membranes. Nano-size materials are able to enhance the physical properties of bulk materials [16]. The large surface area and the smaller size of the nanoparticles have interaction with microbes in a broad range and hence the nanochitosan were selected in this study. Alginate is a copolysaccharide extracted from brown algae consisting of $\mathrm{D}$-mannuronic and L-guluronic acid monomers. By the preferential interaction of calcium ions with the $\mathrm{G}$ moieties, alginate forms 3-dimensional ionotropic hydrogel resulting in the production of an inhomogeneous gel [17]. Alginate based products were currently found to be the most popular fibrous products utilized in developing antimicrobial agents releasing systems or dressing materials [18].

Due to its unique colloidal properties such as suspending, thickening, film forming, stabilizing, gel producing, and emulsion stabilizing properties the alginate has a greater potential to form biopolymer film or coating component [19]. Since the alginate gels exhibit bacteriostatic properties against various microorganisms such as Gram-negative Escherichia coli, Gram-positive Staphylococcus aureus etc., the sodium alginate is utilized in film formation in the present study. The lignocellulosics contribute to their diversity in structure and property [20] and this was due to large number of reactive groups with the wide range of molecular weight, varying chemical composition. The Banana pseudostem has some special properties relating to various phenomena such as antioxidant, permanent staining of cloth and fibers, antimicrobial and antihemorrhagic properties [21]. In recent years the surface modification of fibers, either natural or synthetic, is highly desired [22-24].

During the last few decades, the microcrystalline cellulose extracted from the various lignocellulosic fibers has received much attention and interest due to its excellent properties such as renewability, biodegradability, biocompatibility, nontoxic and high surface area [25] suitable for antimicrobial behavior. A new class of soluble cellulosegrafted hyperbranched polymers has been synthesized through facile "hypergrafting" reaction using bis(2-chloroethyl) amine and soluble cellulose tosylates by Deniz Demircan and Baozhong Zhang [26]. Results suggested that the obtained natural cellulosic materials can act as effective polymeric biocides, and may have great potential in various antimicrobial material applications. Hence based on the reports suggested by various authors, the microcrystalline cellulose was extracted from banana fiber and studied for its antimicrobial behavior in blended form in this work. This study addresses the ways of obtaining and using the blended form of nanochitosan and sodium alginate with microcrystalline cellulose extracted from the banana fiber in the form of film in 4:16:1 ratio as antimicrobial agents against gram positive bacteria Bacillus subtilis and gram negative bacteria $E$. coli due to the problem of resistance of many infectious agents to the usual treatments. The results were investigated.

\section{Materials}

Chemicals such as the sodium alginate, sodium hypochlorite, oxalic acid and sodium hydroxide were purchased from Nice chemicals Pvt Ltd, India and Central Drug House Pvt Ltd, New Delhi. The solvent glacial acetic acid were obtained from Sisco Research Laboratories Pvt Ltd, Mumbai and the crosslinking agents namely sodium tripolyphosphate, $\mathrm{CaCl}_{2} \cdot 2 \mathrm{H}_{2} \mathrm{O}$ were procured from Finar chemicals Ltd, Ahmedabad, Nice chemicals PvtLtd, India respectively. In addition, the banana fiber was collected from local farms and the chitosan biopolymer (92\% deacetylated) was procured from India Sea Foods, Cochin, Kerala. All the chemicals used in the present research work were of analytical grade.

\section{Materials and Methods}

\section{Extraction of microcrystalline cellulose from banana fiber by steam explosion process}

As per the procedure reported by Bibin Mathew cherian and his coworkers [27], the isolation of microcrystalline cellulose from the banana fiber was done using the steam explosion method. The complete extraction of microcrystalline cellulose from banana fiber was done by the combined chemical (acidic) and mechanical treatments. Initially the steam explosion of the chopped lignocellulosic banana fibers (30 g) with $2 \% \mathrm{NaOH}$ (fiber to liquor ratio 1:10) solution was carried out in anautoclave at a pressure of $20 \mathrm{lb}$ for a period of $1 \mathrm{~h}$. The steamed alkali treated fibers was then bleached using a mixture of acetic acid and sodium hypochlorite solution, further treated with oxalic acid and stirred mechanically well to extract the cellulose completely with different degrees of crystallinity. The photograph of the prepared four stages of fiber was represented in Figure 1.

\section{Preparation of nanochitosan}

In the present work, the nanochitosan was synthesized from the chitosan using sodium tripolyphosphate as a crosslinking agent by ionotropic gelation method as per the procedure reported by Govindarajan and his coworkers [28]. Initially in order to create the homogeneous chitosan solution, about $1 \mathrm{~g}$ of chitosan dissolved in 200 $\mathrm{ml}$ of $2 \%$ acetic acid solution was kept under magnetic stirring process for about $20 \mathrm{~min}$. Then to the above prepared chitosan solution, 0.8 $\mathrm{g}$ of sodium tripolyphosphate dissolved in $107 \mathrm{ml}$ of conductivity water was added drop wise and stirred well for about $30 \mathrm{~min}$ to reach equilibrium. A milky colored emulsion like appearance of chitosan nanoparticles were formed upon the ionic cross linking between the sodium tripolyphosphate and chitosan solution. After reaching equilibrium, the supersaturated solution was decanted and the thick emulsion of nanochitosan settled at the bottom of beaker was poured into the petri plates and it is allowed to dry for few hours. A photograph of the nanochitosan prepared from chitosan was shown in Figure 2.

\section{Preparation of NCS/SA/MC (4:16:1) film}

Ternary biopolymeric film was prepared by mixing the nanochitosan, sodium alginate and microcrystalline cellulose extracted from the banana fiber in certain ratio. Three solutions were prepared: (i) an aqueous $5 \%$ nanochitosan solution; (ii) aqueous $20 \mathrm{wt} \%$ alginate solution and (iii) aqueous $1.25 \mathrm{wt} \%$ micro-crystalline cellulose solution. An emulsion was formed by blending above prepared solutions at 500

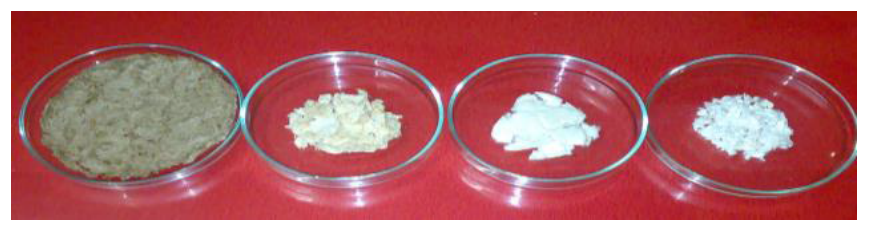

(i)

(ii)

(iii)

(iv)

Figure 1: Photograph of i) Steam exploded fiber ii) Bleached fiber iii) Acidically treated fiber, iv) Mechanically treated fiber. 
Citation: Vijayalakshmi K, Devi BM, Sudha PN, Venkatesan J, Anil S (2016) Synthesis, Characterization and Applications of Nanochitosan/Sodium Alginate/Microcrystalline Cellulose Film. J Nanomed Nanotechnol 7: 419. doi: 10.4172/2157-7439.1000419

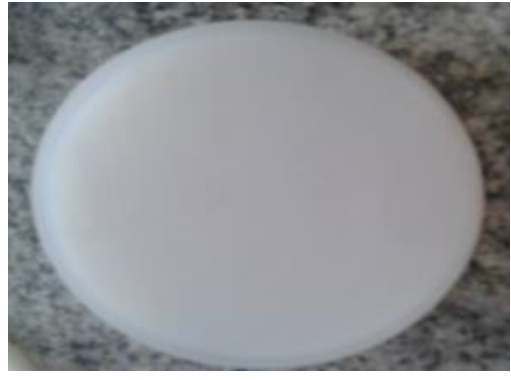

Figure 2: Photograph of the nanochitosan prepared from chitosan.

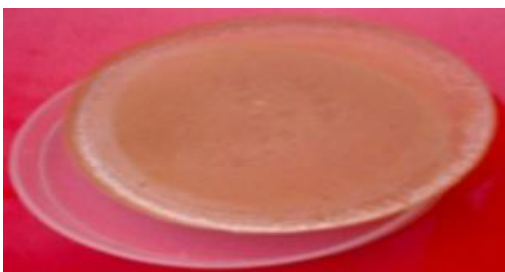

Figure 3: Photograph of the prepared NCS/SA/MC film (2:8:1).

rpm for about $30 \mathrm{~min}$. After this process is over the above prepared emulsion was fabricated evenly onto the petri plates, allowed to dry for few hours and these dried films were then soaked in a $0.2 \mathrm{M}$ calcium chloride solution for about 3 hours. Finally the NCS/SA/MC films were rinsed with double distilled water to remove any excess $\mathrm{CaCl}_{2}$ on the film and dried for 24 hours. A photograph of the prepared NCS/SA/ MC film was shown in Figure 3.

\section{Characterization}

\section{Fourier transform infra red spectroscopy studies}

The Perkin Elmer 200 FTIR spectrophotometer instrument was utilized in recording the FT-IR spectrum of the prepared samples in the wave number range from $4000 \mathrm{~cm}^{-1}$ to $450 \mathrm{~cm}^{-1}$ during 64 scans, with $2 \mathrm{~cm}^{-1}$ resolution.

\section{X-Ray diffraction studies}

The X-ray diffraction patterns of NCS/SA/MC film was measured using X-ray powder diffractometer (XRD- SHIMADUZ XD-D1) with $\mathrm{Ni}$ filter $\mathrm{Cu} \mathrm{Ka}$ radiation source $(\lambda=0.154 \mathrm{~nm})$, set at scan rate $=10^{\circ}$ \% min, using a voltage of $40 \mathrm{kv}$ and a current of $30 \mathrm{~mA}$.

\section{Thermogravimetric analysis}

Thermogravimetric analysis of the prepared samples was performed using SDT Q600 V8.0 Build 95 instrument. The range of temperature used is between $30^{\circ} \mathrm{C}$ to $750^{\circ} \mathrm{C}$ with a heating rate of $10^{\circ} \mathrm{C} / \mathrm{min}$ under nitrogen atmosphere.

\section{Differential scanning calorimetric analysis}

The DSC studies of the prepared samples were carried out using DSC Q10 V 9.0 Build 275 instrument in the temperature range between $30^{\circ} \mathrm{C}$ to $350^{\circ} \mathrm{C}$ with the heating rate of $10^{\circ} \mathrm{C} / \mathrm{min}$.

\section{Scanning electron microscopic studies}

The surface morphology of the prepared samples was examined with the Scanning Electron Microscope (Zeiss EVO 40). The photographs of the various cross sectional morphologies of the NCS/SA/MC film samples were taken at different magnifications.

\section{Antibacterial activity}

Two bacterial strains namely Bacillus Subtilis - gram positive bacteria and Escherichia Coli-gram negative bacteria were utilized to investigate the antibacterial activity of the NCS/SA/MC film by diffusion method using Muller Hinton Agar (MHA) medium. The microorganisms Escherichia coli and Bascillus subtilis were inoculated initially on Muller Hinton Agar (MHA) medium and spread uniformly using sterile spreader in Petri plates. After solidification of the MHA medium, a small amount of the NCS/SA/MC film prepared in 4:16:1 ratio were then placed on different cultured agar plates and the plates were incubated on individual racks for $24 \mathrm{~h}$ at $37^{\circ} \mathrm{C}$. The evaluation of the antibacterial activities of the prepared samples was done by measuring the diameter of zone of inhibition grown around the samples against the test microorganisms using the ruler.

\section{Results and Discussion}

\section{FT-IR spectral analysis}

Fourier transform infrared spectroscopic (FTIR) analysis mainly provides information about the functional properties which correlate functional group and structure of composite blended film [29].

The FT-IR spectral details of chitosan and nanochitosan was represented in Table 1 and Figure 4. The FT-IR spectral details of pure chitosan (Figure 4a) showed that the hydroxyl $(\mathrm{OH})$ peaks can be assigned at $3454.75 \mathrm{~cm}^{-1}$ and alkyl $\mathrm{C}-\mathrm{H}$ stretching vibration were identified as doublets at $2923.08 / 2830.05 \mathrm{~cm}^{-1}$ respectively [30,31] Strong peaks observed at $1628.87 \mathrm{~cm}^{-1}, 1540.02 \mathrm{~cm}^{-1}$ and $1421.52 \mathrm{~cm}^{-1}$ showing the presence of $\mathrm{C}=\mathrm{O}$ stretching (amide-I band) [32], N-H bending and $\mathrm{C}-\mathrm{H}$ deformation respectively.

\begin{tabular}{|l|c|c|}
\hline Responsible groups & $\begin{array}{c}\text { Chitosan } \\
\text { Wavenumbers } \mathbf{( \mathbf { c m } ^ { - 1 } \mathbf { ) }}\end{array}$ & $\begin{array}{c}\text { Nanochitosan } \\
\text { Wavenumbers } \mathbf{( c m}^{-1} \mathbf{)}\end{array}$ \\
\hline $\mathrm{OH}$ stretching and $\mathrm{NH}$ stretching & 3454.75 & 3385.92 \\
\hline Aliphatic $\mathrm{CH}$ stretching in $\mathrm{CH}_{2}$ & 2923.08 & 2920.57 \\
\hline $\mathrm{C}=\mathrm{O}$ in $2^{\circ}$ Amide & 1628.87 & 1635.20 \\
\hline $\mathrm{NHBending}$ & 1540.02 & 1510.05 \\
\hline $\mathrm{P}=\mathrm{O}$ stretching & --- & 1219.00 \\
\hline P-O stretching & --- & 1038.87 \\
\hline
\end{tabular}

Table 1: FT-IR spectral details of chitosan and nanochitosan.

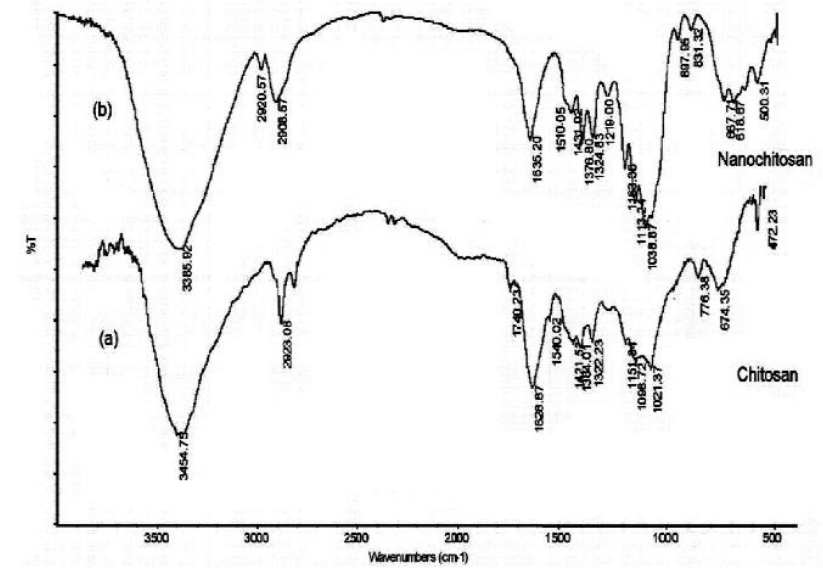

Figure 4: FT-IR spectrum of (a) pure chitosan (b) Nanochitosan. 
Figure $4 \mathrm{~b}$ represents the FT-IR spectral details of nanochitosan prepared from the chitosan using ionotropic gelation method. The absorption band obtained at $3385.92 \mathrm{~cm}^{-1}$ attributed to $-\mathrm{NH}$ group in chitosan was broadened by the physical interactions with TPP [33]. Strong peaks obtained at $2920.57 \mathrm{~cm}^{-1}, 2908.57 \mathrm{~cm}^{-1}, 1635.23 \mathrm{~cm}$ ${ }^{1}, 1510.05 \mathrm{~cm}^{-1}, 1376.80 \mathrm{~cm}^{-1}$ and $1219.00 \mathrm{~cm}^{-1}$ indicate the presence of asymmetrical and symmetrical stretching in $\mathrm{CH}_{2}$ group, $\mathrm{NH}_{3}^{+}$ stretching, $\mathrm{C}=\mathrm{O}$ stretching in amides, $\mathrm{NH}$ bending, $\mathrm{OH}$ in plane bending in alcohols and $\mathrm{P}=\mathrm{O}$ stretching [34]. The peak obtained at $1163.38 \mathrm{~cm}^{-1}$ indicated the overlapping peak of $\mathrm{C}-\mathrm{O}$ stretching in polysaccharide and formation of chitosan nanoparticles due to the interaction of ammonium ion and phosphate ion in chitosan nanoparticle molecules [35].

When compared to pure chitosan, the nanochitosan obtained by ionotropic gelation method showed different bands. The shift of the peak observed at $3454.75 \mathrm{~cm}^{-1}$ corresponding to the presence of $\mathrm{NH}, \mathrm{OH}$ stretching in chitosan to lower wavenumber $(3385.92 \mathrm{~cm}$ $\left.{ }^{1}\right)$ in nanochitosan sample indicate that crosslinking had taken place effectively between the sodium tripolyphosphate and the chitosan. This observed results showed that the amide group and $\mathrm{NH}_{2}$ group of chitosan are both slightly crosslinked with a TPP molecule. Also in addition to this, in case of nanochitosan the appearance of some new peaks ( $1210.00 \mathrm{~cm}^{-1}$ due to $\mathrm{P}=\mathrm{O}$ stretching) proves the formation of nanoparticles from the chitosan by ionotropic gelation method.

The nanochitosan/sodium alginate/microcrystalline cellulose (4:16:1) ternary film thus prepared were characterized by FTIR spectral studies. Table 2 and Figure 5 represent the FT-IR spectral details of NCS/SA/MC film prepared in 4:16:1 ratio.

The FTIR spectrum of NCS/SA/MC film (Figure 5) shows a broad adsorption band at $3583.74-3275.13 \mathrm{~cm}^{-1}$ corresponding to the overlapping of $-\mathrm{OH}$ stretching and $-\mathrm{NH}$ stretching bands [36]. The

\begin{tabular}{|l|l|}
\hline Wave number $\left.\mathbf{( c m}^{-1}\right)$ & Responsible Groups \\
\hline 3334.92 & O-H stretching in alcohols (Intermolecular $\mathrm{H}$ bonded) \\
\hline 3275.13 & $\mathrm{~N}-\mathrm{H}$ stretching in amines \\
\hline 2924.09 & Asymmetrical $\mathrm{CH}$ stretching in $\mathrm{CH}_{2}$ group \\
\hline 1612.49 & $\mathrm{C}=\mathrm{O}$ stretching in carboxylate ion \\
\hline 1423.47 & Weak band due to carboxylate ion group \\
\hline 1153.43 & $\mathrm{P}=\mathrm{O}$ stretching \\
\hline 1033.85 & $\mathrm{C}-\mathrm{O}-\mathrm{C}$ linkage \\
\hline 893.04 & $\mathrm{C}-\mathrm{C}$ stretching \\
\hline 821.68 & $\mathrm{~N}-\mathrm{H}$ deformation \\
\hline
\end{tabular}

Table 2: FT-IR spectral details of NCS/SA/MC film.

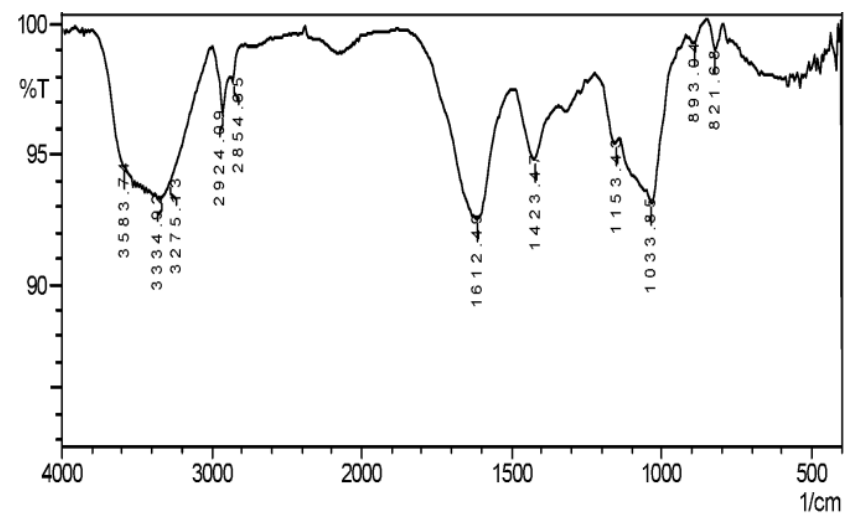

Figure 5: FTIR spectrum of NCS/SA/MC film (4:16:1). appearance of peak at $2924.09 \mathrm{~cm}^{-1}$ indicates the presence of aliphatic asymmetrical C-H stretching in methylenic group respectively [37]. The prominent peaks observed at various wave numbers such as $2854.65 \mathrm{~cm}^{-1}, 1612.49 \mathrm{~cm}^{-1}, 1423.47 \mathrm{~cm}^{-1}, 1153.43 \mathrm{~cm}^{-1}, 1033.85 \mathrm{~cm}$ ${ }^{1}, 893.04 \mathrm{~cm}^{-1}$ and $821.68 \mathrm{~cm}^{-1}$ was attributed toNH ${ }_{3}^{+}$stretching, carbonyl stretching in carboxylate ion, weak band due to carboxylate ion, $\mathrm{P}=\mathrm{O}$ stretching , $\mathrm{C}-\mathrm{O}-\mathrm{C}$ linkage, $\mathrm{C}-\mathrm{C}$ stretching and $\mathrm{NH}$ wagging respectively.

On comparing the FT-IR spectral details of NCS/SA/MC film with nanochitosan it was observed that after the reaction of nanochitosan with alginate and microcrystalline cellulose in ternary NCS/SA/MC film, the stretching vibration of $-\mathrm{OH}$ and $-\mathrm{NH}_{2}$ observed at 3385.92 $\mathrm{cm}^{-1}$ in nanochitosan was shifted to $3334.92 \mathrm{~cm}^{-1}$ and becomes broad, the asymmetrical stretching of $\mathrm{NH}_{3}{ }^{+}$groups was shifted from 2908.57 $\mathrm{cm}^{-1}$ to $2854.65 \mathrm{~cm}^{-1} \mathrm{~cm}^{-1}$ and also a new peak was appeared at 1612.49 $\mathrm{cm}^{-1}$ corresponding to the presence of $\mathrm{C}=\mathrm{O}$ stretching in carboxylate ion. These observed shifts in the frequencies and the appearance of new peak confirms that the nanochitosan and sodium alginate were effectively binded with the cellulose extracted from banana fiber in the prepared film.

\section{$\mathrm{X}$-ray diffraction studies (XRD)}

XRD analysis helps in describing the physical properties of samples in terms of crystalline structure and in addition it also assesses the compatibility of each component material present in the blended films [38]. Table 3, Figure $6 \mathrm{a}$ and $6 \mathrm{~b}$ shows the X-ray diffractogram details and patterns of pure chitosan and nanochitosan.

The X-ray diffractogram of chitosan (Figure 6a) had a semi crystalline nature with two main diffraction peaks at around $2 \theta=10^{\circ}$ and $20^{\circ}$. The semi crystalline nature of pure chitosan was confirmed from the appearance of the diffraction peak centered at diffraction angle $2 \theta-10^{\circ}$ and sharp diffraction peak at $20^{\circ}$ which are indicative of high degree of crystalline morphology [39]. The chitosan molecule easily form the crystalline regions and this may be due to the presence of plenty of $-\mathrm{OH}$ and $-\mathrm{NH}_{2}$ groups in the chitosan structure, which could form stronger inter and intramolecular hydrogen bonds [40].

The X-ray diffraction pattern of nanochitosan obtained using ionic gelation technique is shown in Figure $6 \mathrm{~b}$. The $\mathrm{X}$ ray diffractogram of nanochitosan shows a broad peak at around $2=28^{\circ}$. The broadening of the peaks is due to the deformation of the crystalline regions by the increased packing of chitosan chains by ionic crosslinking [41]. The structure of chitosan molecules has certain regularity and as a result of this the chitosan molecules could form crystalline regions very easily but after crosslinking with tripolyphosphate it shows a decrease in crystallinity of chitosan. This could be attributed due to the deformation of the hydrogen bond in original chitosan by the substitution of hydroxyl and amino groups [42], which efficiently destroyed the regularity of the packing of the original chitosan chains resulting in the formation of amorphous nanochitosan.

From the nature of the broad peak obtained it was concluded that nanochitosan was found to be more amorphous than the pure chitosan. The comparison of XRD results of nanochitosan with pure chitosan reveals that there was a significant shift in the diffraction pattern with

\begin{tabular}{|l|c|c|}
\hline Sample & $\mathbf{2 \theta}$ values & $\begin{array}{c}\text { Degree of crystallinity } \\
\mathbf{( \% )}\end{array}$ \\
\hline Chitosan & $10^{\circ}, 20^{\circ}$ & 7.18 \\
\hline Nanochitosan & $28^{\circ}\left(\right.$ broad $\left.20^{\circ}-40^{\circ}\right)$ & 4.64 \\
\hline
\end{tabular}

Table 3: XRD details of chitosan and nanochitosan. 

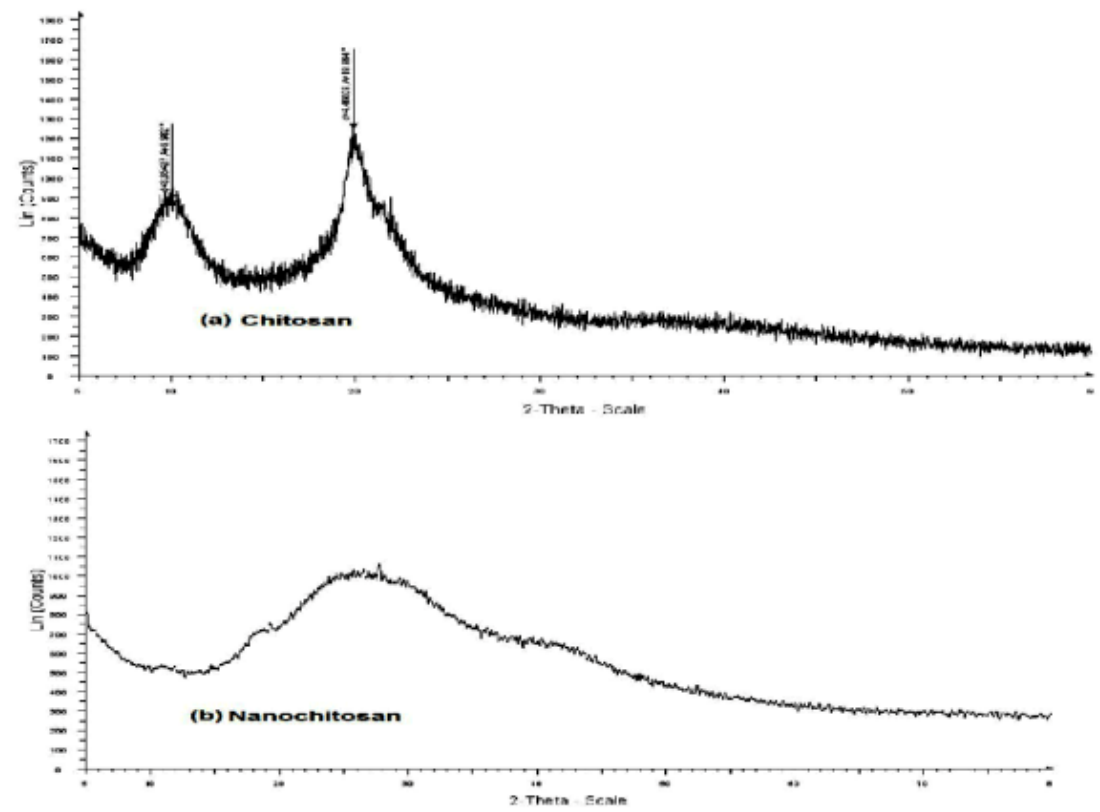

Figure 6: X-ray diffractogram of (a) pure chitosan and (b) nanochitosan.

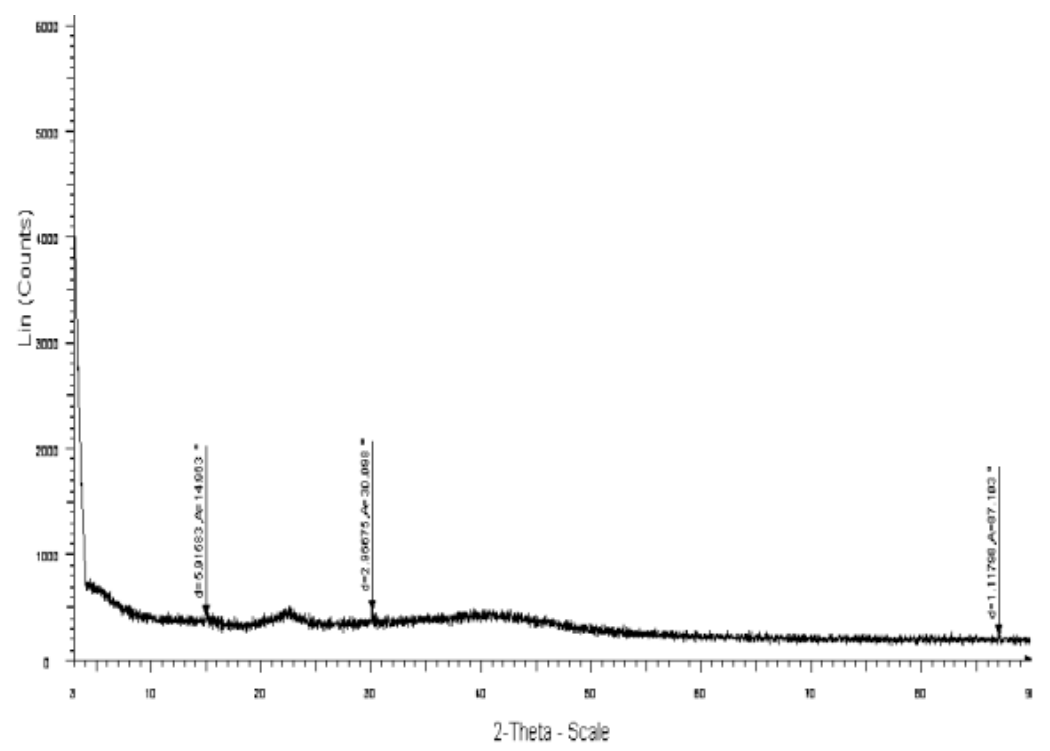

Figure 7: X-ray diffractogram of NCS/SA/MC film (4:16:1).

a broad amorphous peak in nanochitosan and the obtained results indicated that there was an effective crosslinking, molecular miscibility and also certain interaction takes place between the chitosan with the ionic crosslinking agent. The X-ray diffractogram details of NCS/SA/ MC film prepared in 4:16:1 ratio was represented in Figure 7 and Table 4.

The X- ray diffractogram details of NCS/SA/MC film (Figure 7) shows peaks at various $2 \theta$ values such as $14.963^{\circ}, 30.098^{\circ}$ and $87.103^{\circ}$. Due to the dispersion of the polymer matrix in the NCS/ SA/MC film, certain changes in the degree of crystallinity have been occurred. The less intense peak and less crystalline entity (broad nature-more amorphous) obtained in NCS/SA/MC film might be

\begin{tabular}{|c|c|c|}
\hline Sample & $\mathbf{2 \theta}$ values & Degree of crystallinity (\%) \\
\hline NCS/SA/MC film (4:16:1) & $14.963^{\circ}, 30.098^{\circ}, 87.103^{\circ}$ & 4.44 \\
\hline \multicolumn{2}{|c|}{ Table 4: XRD details of NCS/SA/MC film. }
\end{tabular}

due to the destruction of the packing of the polymers by the strong interaction which occurred between the nanochitosan, sodium alginate and microcrystalline cellulose polymers [43]. On comparing the XRD details of NCS/SA/MC film with chitosan and nanochitosan, it was observed that the calculated lower degree of crystallinity values suggests that the prepared NCS/SA/MC film has highly amorphous nature suitable for a variety of applications. 


\section{Thermogravimetric analysis (TGA)}

Thermogravimetric analysis (TGA) is a method of thermal analysis in which changes in physical and chemical properties of materials were measured as a function of increasing temperature (with constant heating rate) or as a function of time [44]. The TGA thermogram details of chitosan was represented in Figure 8.

The TGA thermogram of chitosan presented in Figure 8 shows mainly two major weight losses one before $200^{\circ} \mathrm{C}$ and another after $270^{\circ} \mathrm{C}$ in polymer mass. The first one is due to the elimination of water molecules bound to the two polar groups in chitosan and the second one is due to the dehydration of saccharide rings, depolymerisation and decomposition of volatile products [45]. Maximum weight loss occurs at the temperature range of $217^{\circ} \mathrm{C}-450^{\circ} \mathrm{C}$ and the residual temperature was found to be $850^{\circ} \mathrm{C}$. At the end of the experiment around $69.933 \%$ of the chitosan gets disintegrated within $840^{\circ} \mathrm{C}$ leaving behind $30.067 \%$ of the sample as residue showing higher thermal stability.

The TGA thermogram details of nanochitosan (Figure 9) indicate that the first thermal event occurs at temperature range $50-150^{\circ} \mathrm{C}$ and is accompanied by the weight loss ranging from $8 \%$ to $10 \%$ which may be due to the loss of residual water present in the sample. The maximum weight loss occuring in nanochitosan after $150^{\circ} \mathrm{C}$ may be due to the decomposition of polymer matrix [46]. At the end of the experiment nearly $45.63 \%$ of the sample remained as residue showing the higher thermal stability of nanochitosan. The increased thermal stability indicates the formation of stronger and stiffer hydrogel network as a result of crosslinking.

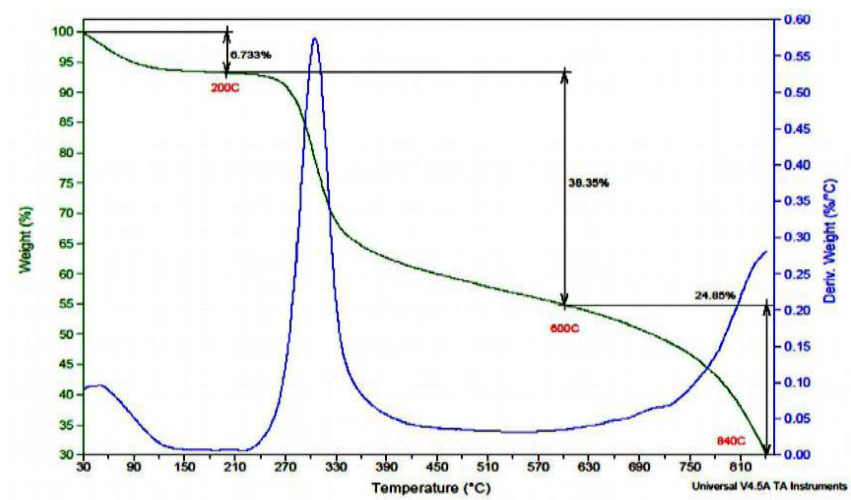

Figure 8: TGA thermo gram of Chitosan.

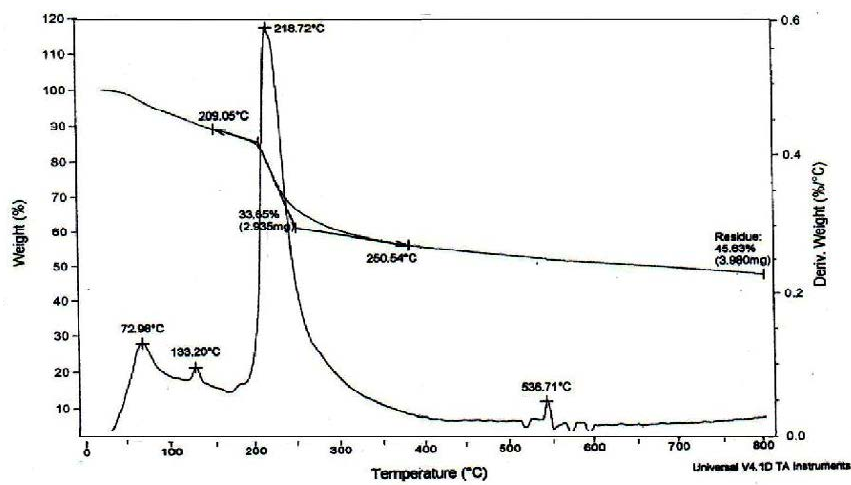

Figure 9: TGA thermo gram of nanochitosan
Figure 1 shows the TGA thermo gram details of NCS/SA/MC film prepared in 4:16:1 ratio. The TGA curve shows that the weight loss occurs mainly in two stages. The first stage weight loss was mainly due to loss of water because the polysaccharides usually have strong affinity of water and hence may be easily hydrated [47]. The second stage weight loss corresponds to the thermal decomposition of main chain of nanochitosan, sodium alginate and microcrystalline cellulose, vaporization and elimination of volatile product. From Figure 7, it was evident that around $65 \%$ of the sample gets disintegrated in the temperature range of $400^{\circ} \mathrm{C}$ and the linear shallow decrease in weight was observed in the temperature range of $250-400^{\circ} \mathrm{C}$. The residual temperature of the sample was found to be $750^{\circ} \mathrm{C}$ and the amount of sample remained as a residue at the end of the experiment was observed to be $21.11 \%$. The obtained higher amount of residue indicates the highly stable thermal behavior. The comparison of TGA thermogram details of NCS/SA/MC film with pure chitosan and nanochitosan indicate that the NCS/SA/MC film was also found to be thermally more stable and this was confirmed from the observed higher decxomposition termperature and the higher amount of residue remained at the end of the experiment.

\section{Differential scanning calorimtery (DSC) studies}

Differential scanning calorimetry (DSC) monitors heat effects associated with phase transitions and chemical reactions as a function of temperature. The DSC thermogram of pure chitosan was shown in Figure 8 .

In Figure 8, the broad endothermic peak obtained at $89.04^{\circ} \mathrm{C}$ and a sharp exothermic peak at $312.26^{\circ} \mathrm{C}$ showing the crystallization and the melting process of polymer at different temperatures. A wide endothermic peak obtained at $89.04^{\circ} \mathrm{C}$ is attributed to the elimination of absorbed water and a sharp exothermic peak at $312.26^{\circ} \mathrm{C}$ is due to the decomposition of chitosan chains [48]. The glass transition temperature of the polymer is observed at $203^{\circ} \mathrm{C}$ and an exothermic peak obtained at $313.26^{\circ} \mathrm{C}$ indicating that certain chemical changes had taken place in this temperature range.

The DSC thermogram details of nanochitosan prepared from chitosan by utilizing the ionotropic gelation method was shown in Figure 9. A broad enothermic peak obtained below $80^{\circ} \mathrm{C}$ is due to the removal of absorbed water and a sharp endothermic peak at $217^{\circ} \mathrm{C}$ is associated with the breakage of chitosan phosphoric acid cross linkage. The glass transition temperature of the nanochitosan was found to be $205^{\circ} \mathrm{C}$ and the higher value of glass transition temperature is due to the presence of crosslinking agent [49].

Figure 10 represents the DSC thermo gram details of NCS/SA MC film prepared in 4:16:1 ratio. Two broad endothermic peaks were observed in the temperature range of $80-100^{\circ} \mathrm{C}$ and $210-260^{\circ} \mathrm{C}$. The glass transistion temperature was found to be $145^{\circ} \mathrm{C}$. The observation of a single glass transition in the DSC heating curves indicates that nanochitosan, sodium alginate and microcrystalline cellulose are highly compatible. The higher onset temperatures are associated with higher thermal stability [50]. From the obtained higher onset temperature and higher value of glass transition temperature, it was concluded that the NCS/SA/MC film prepared in 4:16:1 ratio was also found to be highly thermally stable.

\section{Scanning electron microscopic (SEM) studies}

The scanning electron microscopy (SEM) gives information about the topography, surfaces, structures, morphologies, and forms of materials and composition of the studied material [51]. The SEM 
Citation: Vijayalakshmi K, Devi BM, Sudha PN, Venkatesan J, Anil S (2016) Synthesis, Characterization and Applications of Nanochitosan/Sodium Alginate/Microcrystalline Cellulose Film. J Nanomed Nanotechnol 7: 419. doi: 10.4172/2157-7439.1000419

Page 7 of 11

micrograph details of the pure chitosan and nanaochitosan was represented in Figures 11 and 12.

The SEM micrograph obtained for the pure chitosan (Figure 11) revealed that the texture is plain without pores having smooth, compact and homogeneous even surface structure with no gross effects [52].

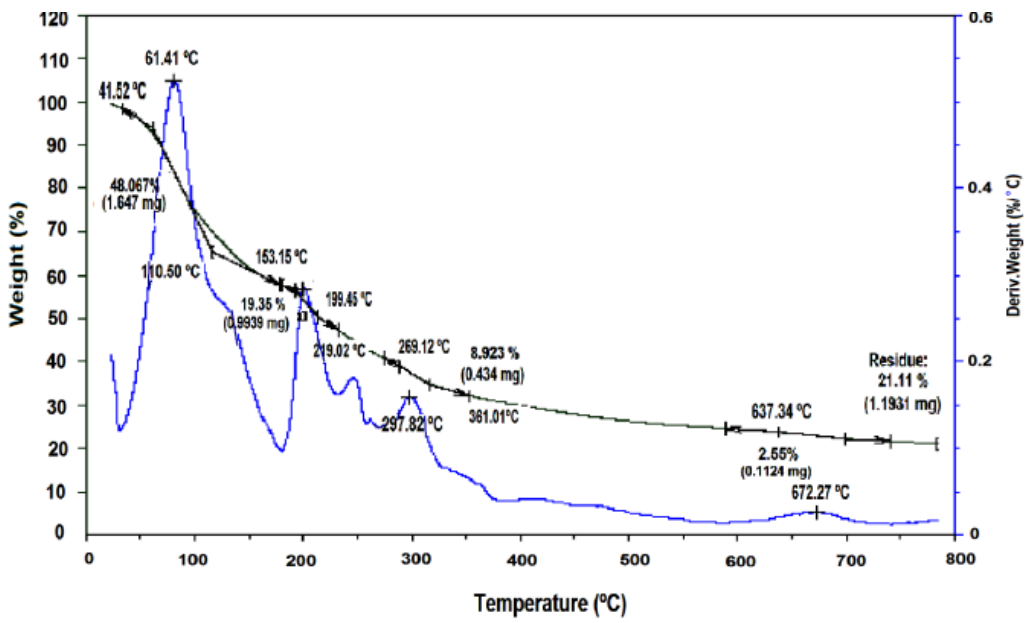

Figure 10: TGA thermo gram of NCS/SA/MC film (4:16:1).

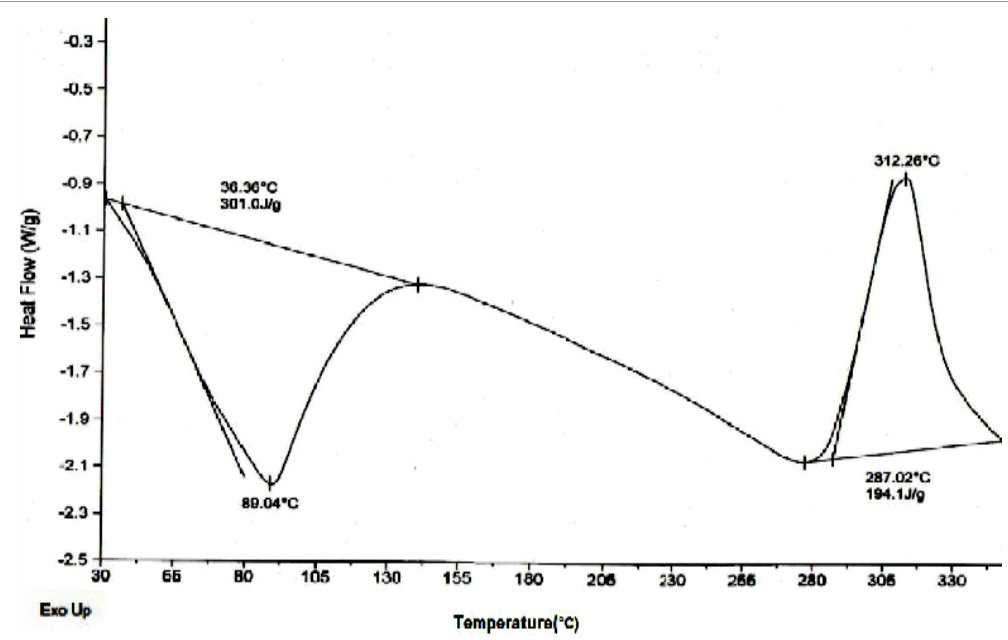

Figure 11: DSC thermogram of pure chitosan.

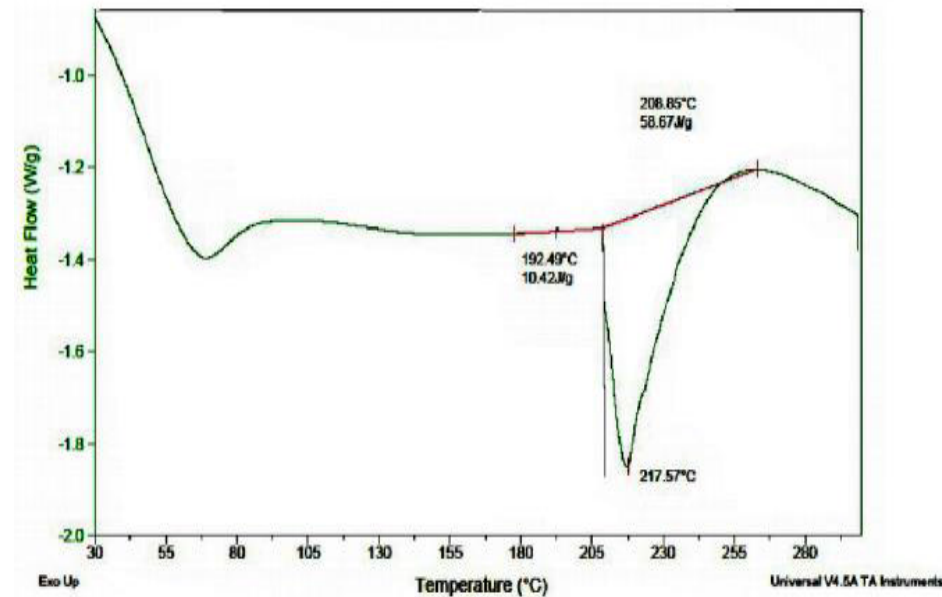

Figure 12: DSC thermogram of nanochitosan. 
the rough surface morphology. The SEM picture of nanochitosan demonstrates the good dispersion of the nanoparticles which are entangled one on the other with a larger exposed surface making the material very suitable for adsorption. Several authors reported that the nanochitosan prepared from chitosan was found to be having the spherical shape [53], whereas the obtained image reveals that the formation of nanoparticles is not spherical shaped but they are in the rod shaped structure which is a peculiar structure. On comparing the SEM micrograph details of nanochitosan with pure chitosan it was observed that the nanochitosan has relatively rougher surface with uneven structure which exhibited highly amorphous feature.

The surface and cross-sectional morphology of the NCS/SA/MC film prepared in 4:16:1 ratio was shown in Figure 13. The scanning electron micrograph of NCS/SA/MC film prepared in 4:16:1 ratio (Figure 13) shows that the cellulose and nanochitosan were coated uniformly with alginate and also it dispersed in the alginate matrix effectively resulting in a very good rough texture and the interfacial adhesion was evidenced between nanochitosan, sodium alginate and microcrystalline cellulose extracted from the banana fiber. The NCS/ SA/MC film prepared in 4:16:1 ratio showed dense structure at lower magnification and some porosity was detected, although these pores were seen to be closed.

\section{Antibacterial activity}

The bioefficacy of the NCS/SA/MC films prepared in 4:16:1 ratio were tested against bacterial strains such as Bascillus subtilis a Gram positive model bacterium and E. coli a Gram negative model bacterium. The zone of inhibition values of the prepared ternary polymeric film against the growth of selected bacteria are given in Table 5 and Figure $14 \mathrm{a}$ and $14 \mathrm{~b}$. The antibacterial activities of the prepared ternary polymeric NCS/SA/MC film samples prepared in various ratios are predicted from the diameter of zone of inhibhition values measured in $\mathrm{mm}$.

Cationic polyelectrolytes, as well as other molecules with a net positive charge are capable of killing microorganisms [54]. Chitosan

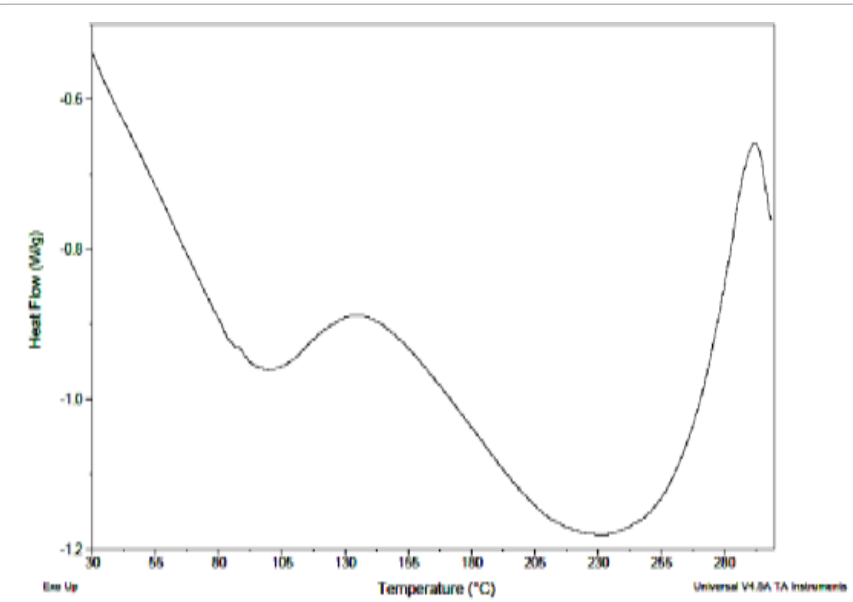

Figure 13: DSC thermogram of NCS/SA/MC film (4:16:1)

\begin{tabular}{|l|c|c|}
\hline \multirow{2}{*}{$\begin{array}{l}\text { Organism } \\
\text { (Bacteria) }\end{array}$} & \multicolumn{2}{|c|}{ Diameter of zone of Inhibition (mm) } \\
\cline { 2 - 3 } & NCS/SA/MC film (4:16:1) & Control Ciproflaxicin \\
\hline Bascillus subtilis & 15 & $17.0 \pm 0.6$ \\
\hline E. coli & 14 & $15.4 \pm 0.6$ \\
\hline
\end{tabular}

Table 5: Antibacterial activity details of NCS/SA/MC film.

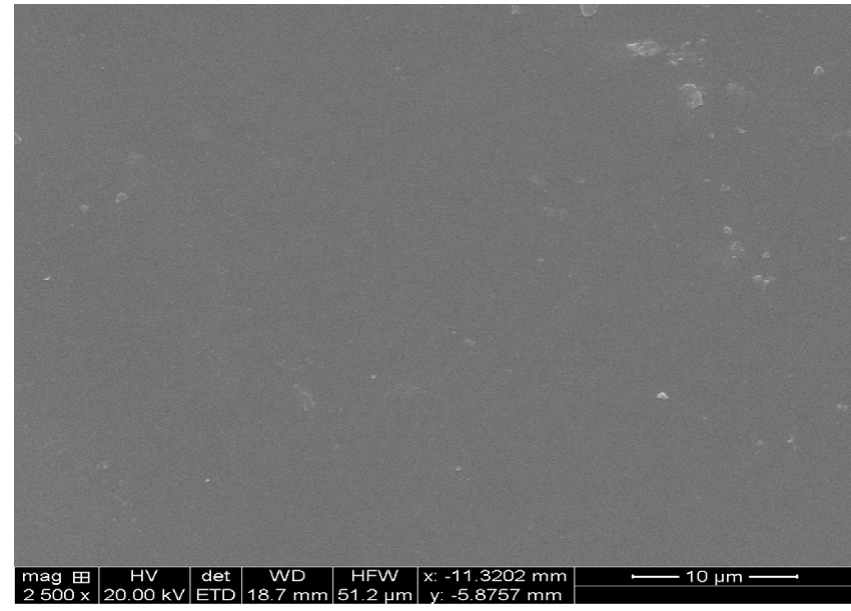

Figure 14: SEM micrograph of chitosan.

is a polycationic material composed of $\mathrm{N}$-acetyl glucosamine and glucosamine units which has antibacterial activity against both gram positive and gram negative bacterial species [55]. The disruption of microbial cell wall by the binding of cationic sites of chitosan to anionic surfaces mainly leads to the cell death [56].

In recent years, various biological activities of chitosan nanoparticles including immunoenhancing effects [57], antitumoral, antifungal, and antimicrobial activities [58] have been reported. The chitosan nanoparticles are successfully being exploited as antimicrobial agents. LiFeng Qi and his coworkers [59] reported that the nanochitosan exhibited higher antibacterial activity than chitosan itself. Based on the special character of the nanoparticles, the chitosan nanoparticles exhibit higher antibacterial activity than chitosan. The chitosan nanoparticles could be well distributed in bacterial suspension after a slight shock for a nice dispersion and hence the bacteria can adhere to the surface of nanochitosan significantly in short time and thus nanochitosan exhibit antibacterial activity.

The target site of the polycation is the negatively charged surface of the bacterial cell. The polycationic nanochitosan with higher surface charge density interact with the bacteria to a greater degree than chitosan itself. The negatively charged surface of the bacterial cell wall interacts effectively to a greater degree with the polycationic nanochitosan $\left(\mathrm{NH}_{3}{ }^{+}\right)$and hinders the growth of the microorganism [60]. Chitosan nano-particles provide higher affinity with bacteria cells for a quantum-size effect, due to the larger surface area of the chitosan nanoparticles, which could be tightly adsorbed onto the surface of the bacteria cells to disrupt the membrane, which would lead to the leakage of intracellular components, thus killing the bacteria cells $[61,62]$.

The potential of chitosan nanoparticles of different sizes evaluated against Escherichia coli (Gram-negative) and Staphylococcus aureus (Gram-positive) by Aakriti Tyagi and her coworkers concludes that the size heterogeneity of chitosan nanoparticles exhibit potent bacteriocidal activity but does not show cytotoxicity on mammalian cells [63].

In addition to this it is also identified that the sodium alginate and cellulosic fibers has higher antibacterial activity. Cellulose fibres were found be an ideal matrix for the design of bioactive, biocompatible, and intelligent materials [64] due to their molecular structure and a large active surface area. Hence based on the reports the NCS/SA/ MC mixture was prepared in the form of film in 4:16:1 ratio and it was tested for the antibacterial activity against two model bacteria 
Citation: Vijayalakshmi K, Devi BM, Sudha PN, Venkatesan J, Anil S (2016) Synthesis, Characterization and Applications of Nanochitosan/Sodium Alginate/Microcrystalline Cellulose Film. J Nanomed Nanotechnol 7: 419. doi: 10.4172/2157-7439.1000419

Page 9 of 11

namely Bascillus subtilis and E. coli. From the observed higher zone of inhibhition values of NCS/SA/MC film presented in Table 5 and Figures 15-17, it was identified that NCS/SA/MC film prepared in 4:16:1 ratio have higher antibacterial activity towards both Bascillus Subtilis and E. coli. When compared to the gram negative bacteria (E. coli), the NCS/SA/MC film exhibits higher antibacterial activity against Gram-positive bacteria (Bacillus subtilis) and this was due to their different cell walls. In case of gram positive bacterium, the cell wall is fully composed of peptide polyglycogen and since the peptidoglycan layer is composed of networks with plenty of pores it allows the foreign molecules to come into the cell without difficulty. But in case of gramnegative bacterium, since the cell wall is made up of a thin membrane of peptide polyglycogen and an outer membrane constituted of lipopolysaccharide, lipoprotein and phospholipids which is a bilayer, it acts as a potential barrier against foreign molecules to enter into cell wall [65-68].

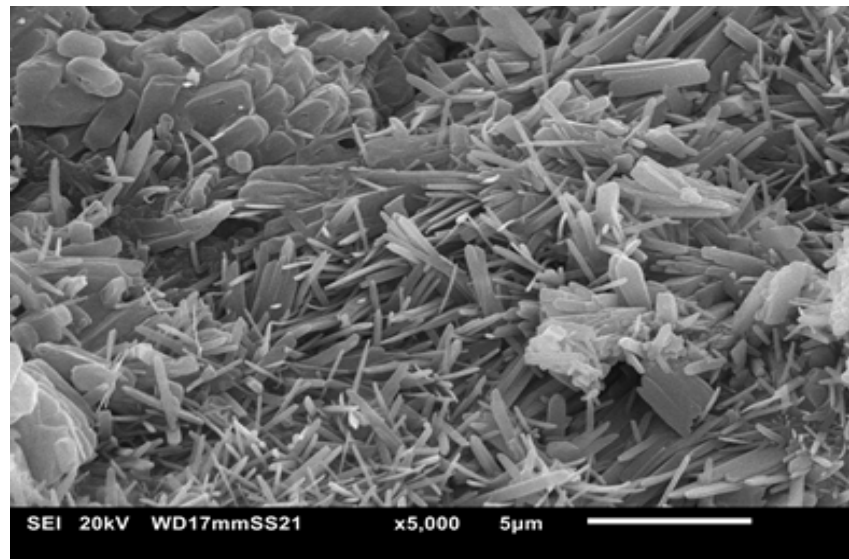

Figure 15: SEM micrograph of nanochitosan
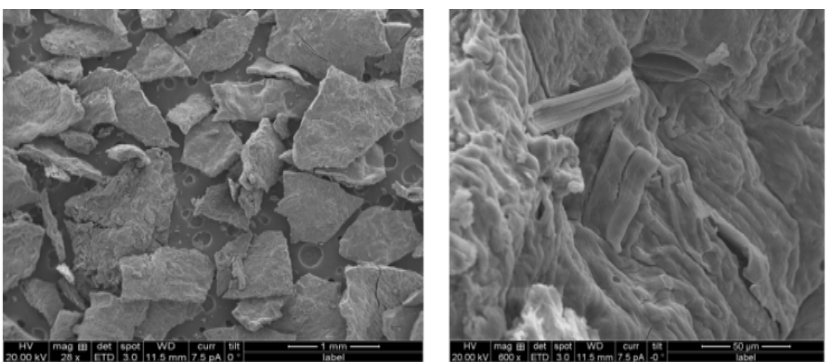

Figure 16: SEM micrograph details of NCS/SA/MC film.

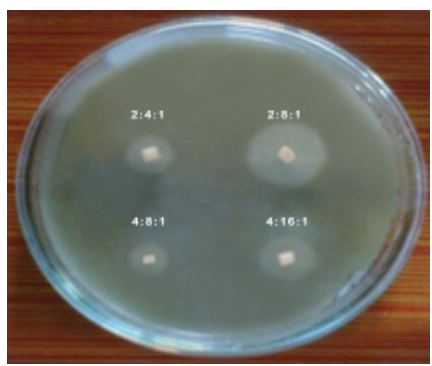

(a)

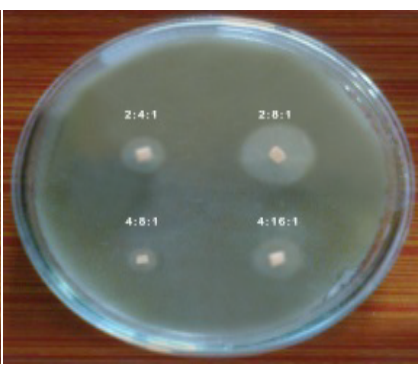

(b)
Figure 17: Antibacterial activity of NCS/SA/MC film (4:16:1) against (a) Bascillus subtilis and (b) E. coli.
According to the standard antibacterial test "SNV 195920-1992", specimens showing more than $1 \mathrm{~mm}$ microbial zone inhibition can be considered as good antibacterial agents [69]. In the present study since the NCS/SA/MC film prepared in all ratios shows the inhibitory zone greater than $1 \mathrm{~mm}$ it was concluded that NCS/SA/MC film prepared in 4:16:1 ratio acts as good antibacterial agent and effective in killing the microbes.

\section{Conclusion}

The strong interaction had taken place effectively between the molecular chains of nanochitosan, sodium alginate and microcrystalline cellulose which may lead to the miscibility at specific ratios of the three components. From FT-IR results it was evident that, in the prepared ternary NCS/SA/MC film, the peaks were observed due to the various functional groups $(\mathrm{OH}, \mathrm{COO}-, \mathrm{NH})$ present in three added polymeric components. The XRD studies elucidate the highly amorphous nature of the NCS/SA/MC film. The TGA and DSC studies clearly indicate that the prepared film was found to be highly thermally stable and the rough surface morphology was identified from the SEM studies. The results of this study showed the potent anti-microbial effect of NCS/ SA/MC film against Bacillus subtilis and E. coli and hence the NCS/SA/ $\mathrm{MC}$ film can be used for future application in antimicrobial therapy.

\section{Acknowledgments}

The authors are thankful to D.K.M College for Women, Vellore, VIT University, Vellore for providing research facilities, co- operation and constant encouragement to carry out the work.

\section{References}

1. Matthews L, Kanwar RK, Zhou S, Punj S, Kanwar JR (2010) Applications of Nanomedicine in Antibacterial Medical Therapeutics and Diagnostics. The Open Tropical Medicine Journal 3: 1-9.

2. Pandey S, Ramontja J (2016) Sodium alginate stabilized silver nanoparticlessilica nanohybrid and their antibacterial Characteristics. Int J Biol Macromol.

3. Angebault C, Andremont A (2013) Antimicrobial agent exposure and the emergence and spread of resistant microorganisms: issues associated with study design. Eur J Clin Microbiol 32: 581-595.

4. Sharma K, Sharma V, Pistor CS, Chaudhary B, Swart SC (2016) J Bioactive Comp Polym 1-18.

5. Salah SM (2012) Antibacterial Activity and UV Protection Property of Some Egyptian Cotton Fabrics Treated with Aqueous Extract from Banana Peel. Int J Cloth Sci 1: 1-6.

6. Mandal SM, Roy A, Ghosh AK, Hazra TK, Basak A, et al. (2014) Challenges and future prospects of antibiotic therapy: from peptides to phages utilization. Front Pharmacol 5: 105-110.

7. Liu XF, Guan YL, Yang DZ, Li Z, Yao KD (2000) Antibacterial action of chitosan and carboxymethylated chitosan. J Appl Polym Sci 79: 1324-1335.

8. Lee S, Cho JS, Cho G (1999) Antimicrobial and Blood Repllent Finishes for cotton and Nonwoven Fabrics Based in Chitosan and Fluoropolymers. Textile Res J 69: 104-112.

9. Chun YW, Webster TJ (2009) The role of nanomedicine in growing tissues. Ann Biomed Eng 37: 2034-2047.

10. Weir E, Lawlor A, Whelan A, Regan F (2008) The use of nanoparticles in antimicrobial materials and their characterization. Analyst 133: 835-845.

11. Ravi Kumar MNV (2000) A review of chitin and chitosan applications. Reactive and functional polymers 46: 1-27.

12. Senel S, McClure SJ (2004) Potential applications of chitosan in veterinary medicine. Adv drug del Rev 56: 1467-1480.

13. Helander IM, Nurmiaho-Lassila EL, Ahvenainen R, Rhoades J, Roller S (2001) Chitosan disrupts the barrier properties of the outer membrane of gramnegative bacteria. Food Microbiol 71: 235-244.

14. Tamer Tamer M, Hassan Mohamed A, Omer Ahmed M, Baset Walid MA 
Citation: Vijayalakshmi K, Devi BM, Sudha PN, Venkatesan J, Anil S (2016) Synthesis, Characterization and Applications of Nanochitosan/Sodium Alginate/Microcrystalline Cellulose Film. J Nanomed Nanotechnol 7: 419. doi: 10.4172/2157-7439.1000419

Hassan Mohamed E, et al. (2012) Synthesis, characterization and antimicrobial evaluation of two aromatic chitosan Schiff base derivatives. Proc Biochem.

15. Tan H, Ma R, Lin C, Liu Z, Tang T (2013) Quaternized chitosan as an antimicrobial agent: Antimicrobial activity, mechanism of action and biomedical applications in orthopedics. Int J Mol Sci 14: 1854-1869.

16. Vellingiri K, Ramachandran T, Senthilkumar M (2013) Eco-friendly Application of Nano Chitosan in Antimicrobial Coatings in the Textile Industry. Nanoscience and Nanotechnology 3: 75-89.

17. Larsen B, Smidsrød O, Painter TJ, Haug A (1970) Calculation of the nearestneighbour frequencies in fragments of alginate from the yields of free monomers after partial hydrolysis. Acta Chem Scand 24: 726-728.

18. Mary Grace, Navin Chand, Sunil Kumar Bajpai (2009) Copper Alginate-Cotton Cellulose (CACC) Fibers with Excellent Antibacterial Properties. J Eng fibers Fab 4: 24-35.

19. King AH (1982) Brown Seaweed extracts (alginates). In M. Glicksman Ed.; Food hydrocolloids (Boca Raton: CRC Press).

20. Dragnevska M (2013) UCTM, Sofia.

21. Kumar RP, Srivastava S, Singh KK, Mathad C, Thind PS (2014) Study of Antioxidant and Antimicrobial Properties, Phytochemical screening and analysis of Sap Extracted from Banana (Musa acuminata) pseudostem. Int J Adv Biotechnol Res 5: 649-658.

22. Grigoray O, Wondraczek H, Heikkilä E, Fardim P, Heinze T (2014) Photoresponsive cellulose fibers by surface modification with multifunctional cellulose derivatives. Carbohydr Polym 111: 280-287

23. Kalia S, Boufi S, Celli A, Kango S (2014) Nanofibrillated cellulose: surface modification and potential applications. Coll Polym Sci 292: 5-31.

24. Li S, Han K, Rong H, Li X, Yu M (2014) Surface modification of aramid fibers via ammonia-plasma treatment. J Appl Polym Sci 131.

25. Trache D, Donnot A, Khimeche K, Benelmir R, Brosse N (2014) Physicochemical properties and thermal stability of microcrystalline cellulose isolated from Alfa fibres. Carbohydr Polym 104: 223-230.

26. Demircan D, Zhang B (2017) Facile synthesis of novel soluble cellulosegrafted hyperbranched polymers as potential natural antimicrobial materials. Carbohydrate Polym 157: 1913-1921.

27. Cherian BM, Pothan LA, Nguyen-Chung T, Menning G, Kottaisamy M, et al (2008) A novel method for the synthesis of cellulose nanofibril whiskers from banana fibers and characterization. J Agri Food Chem 56: 5617-5627.

28. Govindarajan C, Ramasubramaniam S, Gomathi T, Narmadha Devi A Sudha PN (2011) Sorption studies of $\mathrm{Cr}$ (VI) from aqueous solution using nanochitosan-carboxymethyl cellulose blend. Arch Appl Sci Res 3: 127-138.

29. Jahit IS, Nazmi NNM, Isa MIN, Sarbon NM (2016) Preparation and physical properties of gelatin/CMC/chitosan composite films as affected by drying temperature. Int Food Res J 23: 1068-1074.

30. Adina C, Florinela F, Abdelmoumen T, Carmen S (2010) Application of FTIR spectroscopy for a rapid determination of some hydrolytic enzymes activity on sea buckthorn substrate. Rom Biotechnol Lett 15: 5738-5744

31. Lichawska ME, Bodek KH, Jezierska J, Kufelnicki A (2014) Coordinative interaction of microcrystalline chitosan with oxovanadium (IV) ions in aqueous solution. Chem Central J 8: 50.

32. Dinesh Wanule JV, Balkhande, Ratnakar PU, Kulkarni AN, Bhowate CS (2014) Extraction and FTIR Analysis of Chitosan from American cockroach, Periplaneta Americana. Int J Eng Sci Innov Technol 3: 299-304.

33. Ibezim EC, Andrade CT, Marcia C, Barretto B, Odimegwu DC, et al. (2011) Malonically Cross-linked Chitosan/TPP Microparticles for the Controlled Delivery of Pyrimethamine. Ibnosina J Med B S 3: 77-88.

34. Lee ST, Mi FL, Shen YJ, Shyu SS (2001) Equilibrium and kinetic studies of copper (II) ion uptake by chitosan-tripolyphosphate chelating resin. Polymer 42: $1879-1892$

35. Hosseini SF, Zandi M, Rezaei M, Farahmandghavi F (2013) Two-step method for encapsulation of oregano essential oil in chitosan nanoparticles: preparation, characterization and in vitro release study. Carbohydr Polym 95: 50-56.

36. Shanthi $P$, Kothai S (2015) Synthesis and Characterization of Chitosan with Incorporated Herb - A Novel Bionano Composite. Int J Chem Tech Res 8: 208-214.
37. Trung TS, Bao HND (2015) Physicochemical Properties and Antioxidant Activity of Chitin and Chitosan Prepared from Pacific White Shrimp Waste Hindawi Publishing corporation. Int J Carbohydr Chem 2015: 1-6.

38. Su JF, Yuan XY, Huang Z, Wang XY, Lu XZ, et al. (2012) Physicochemical properties of soy protein isolate/carboxymethyl cellulose blend films crosslinked by Maillard reactions: color, transparency and heat-sealing ability. Mater Sci Eng C 32: 40-46.

39. Kumar S, Dutta J, Dutta PK (2009) Preparation and characterization of $\mathrm{N}$-heterocyclic chitosan derivatives based gels for biomedical applications. In J Biol Macromol 45: 330-337.

40. Ramya R, Sudha PN, Mahalakshmi J (2012) Preparation and characterization of chitosan binary blend. Int J Scientific Res Pub 2: 1-9.

41. Martinez-Camacho AP, Cortez-Rocha MO, Ezquerra-Brauer JM, GracianoVerdugo AZ, Rodriguez-Felix et al. (2010) Chitosan composite films: Thermal structural, mechanical and antifungal properties. Carbohydr Polym 82: 305-315.

42. Raut AR, Khairkar SR (2014) Study of chitosan crosslinked with glutaraldeyde as biocomposite material. World J Pharm Res 3: 523-532.

43. Elmotasem $\mathrm{H}$ (2008) Chitosan-alginate blend films for the transdermal delivery of meloxicam. Asian J pharm Sci 3: 12-29.

44. Coats AW, Redfern JP (1963) Thermogravimetric Analysis: A Review. Analys 88: 906-924.

45. Ling-hao He, Xue R, De-bin Y, Liua Y, Song R (2009) Chinese. J Polym Sci 27: $501-510$.

46. Ramli RA, Adnan R, Bakar MA, Masudi SM (2011) Synthesis and Characterization of Pure Nanoporous Hydroxyapatite. J Phys Sci 22: 25-37.

47. Al Sagheer FA, Al-Sughayer MA, Muslim S, Elsabee MZ (2009) Extraction and characterization of chitin and chitosan from marine sources in Arabian Gulf. Carbohydr Polym 77: 410.

48. Sivakami MS, Gomathi T, Venkatesan J, Jeong HS, Kim SK, et al. (2013) Preparation and characterization of nanochitosan for treatment wastewaters Int J Biol macromol 57: 204- 212.

49. Sivakami MS (2013) Thesis. Thiruvalluvar University.

50. Carrillo F, Colom X, Sunol JJ, Saurina J (2004) Structural FTIR analysis and thermal characterization of lyocell and viscose-type fibres. Eur Polym J 40: 2229-2234.

51. Saravanan A, Karthika Prasad, Gokulakrishnan N, Somanathan T (2014) Efficiency of transition metals in combustion catalyst for high yield and well graphitised helical multiwalled carbon nanotubes. Adv Sci Eng Med 6: 809-813.

52. Mollah MZI, Akter N, Quader FB, Sultana S, Khan RA (2016) Biodegradable Colour Polymeric Film (Starch-Chitosan) Development: Characterization fo Packaging Materials. Open Journal of Organic Polymer Materials 6: 11-24.

53. Zhang QP, Xia WS (2008) Physico chemical properties of chitosan based films. Food Technol Biotechnol 46: 262-269.

54. Gomesa AP, Manob JF, Joao Queirozd A, Isabel CG (2013) Layer-by-layer deposition of antimicrobial polymers on cellulosic fibers:new strategy to develop bioactive textiles. Polym Adv Technol 24: 1005-1010.

55. Chattopadhyay DP, Inamdar MS (2013) Improvement in the properties of cotton fabric through synthesized nano chitosan application. Ind J Fibre Text Res 38: 14-21.

56. Inamdar MS, Chattopadhay DP (2006) Chitosan and its versatile applications in textile processing. Manmade Text India 49: 211-216.

57. Verma AK, Kumar V, Agarwal S, Leekha A, Tyagi A, et al. (2013) Interplay of Immune Response and Oxidative Stress Induced By Chitosan Nanoparticles to Possibly Combat Inflammation. World Res J Biosci 1: 028-034.

58. Dutta PK, Dutta J, Tripathi VS (2004) Chitin and Chitosan: Chemistry, properties and applications. J Sci Industrial Res 63: 20-31.

59. Lifeng Qi, Zirong Xu, Xia Jiang, Caihong Hu, Xiangfei Zou (2004) Preparation and antibacterial activity of chitosan nanoparticles. Carbohydr. Res 339: 2693 2700 .

60. Zheng LY, Zhu JF (2003) Study on antimicrobial activity of chitosan with different molecular weight. Carbohydr Polym 54: 527-530.

61. Avadi M, Sadeghi A, Tahzibi A, Bayati K, Pouladzadeh M, et al. (2004) 
Citation: Vijayalakshmi K, Devi BM, Sudha PN, Venkatesan J, Anil S (2016) Synthesis, Characterization and Applications of Nanochitosan/Sodium Alginate/Microcrystalline Cellulose Film. J Nanomed Nanotechnol 7: 419. doi: 10.4172/2157-7439.1000419

Diethylmethyl chitosan as an antimicrobial agent: Synthesis, characterization and antibacterial effects. Eur Polym J 40: 1355-1361.

62. Abdel-Fattah WI, Sallam ASM, Attawa N, Salama E, Maghraby AM, et al. (2012) Functionality, antibacterial efficiency and biocompatibility of nanosilver/ chitosan/silk/phosphate scaffolds 1. Synthesis and optimization of nanosilver/ chitosan matrices through gamma rays irradiation and their antibacterial activity. Materials Research Express 1: 024-035.

63. Tyagi A, Agarwal S, Leekha A, Verma AK (2014) Effect of Mass and Aspect Heterogeneity of Chitosan Nanoparticles on Bactericidal Activity. Int J Adv Res 2: 357-367.

64. Stashak ST, Farstvedt E, Othis A (2004) Update on Wound Dressings: Indication and Best Use. Clinical Techniques in Equine Practice 3: 148-163.
65. Jia Z, Xu W (2001) Synthesis and antibacterial activities of quaternary ammonium salt of chitosan. Carbohydr Res 333: 1-6.

66. No HK, Park NY, Lee SH, Meyers SP (2002) Antibacterial activity of chitosans and chitosan oligomers with different molecular weights. Int J Food Microbio 74: $65-72$.

67. Lu Y, Cheng D, Lu S, Huang F, Li G (2014) Preparation of quaternary ammonium salt of chitosan nanoparticles and their textile properties on Antheraea pernyi silk modification. Text Res J 84: 2115-2124.

68. Abou-Zeid N, Waly A, Kandile N, Rushdy A, El-Sheikh M, et al. (2011) Preparation, characterization and antibacterial properties of cyanoethylchitosan/ cellulose acetate polymer blended films. Carbohydr Polym 84: 223-230.

69. Pollini M, Russo M, Licciulli A, Sannino A, Maffezzoli A (2009) Characterization of antibacterial silver coated yarns. J Mater Sci Mater Med 20: 2361-2366. 